\title{
Advanced supplier selection: A hybrid multi-agent negotiation protocol supporting supply chain dyadic collaboration
}

\author{
Maryam Nejma ${ }^{a}$, Firdaous Zair ${ }^{b^{*}}$, Abdelghani Cherkaoui ${ }^{a}$ and Mohamed Fourka ${ }^{b}$
}

${ }^{a}$ EMISys Team, Engineering $3 S$ Research Center, Mohammadia School of Engineering, Rabat, Morocco

${ }^{b}$ Department of Mechanical Engineering, Faculty of Sciences and Technics, University of Abdelmalek Essaadi, Tangier, Morocco

\begin{tabular}{l}
\hline C H R O N I C L E \\
\hline Article history: \\
Received March 12, 2018 \\
Received in revised format: \\
July 7, 2018 \\
Accepted July 7, 2018 \\
Available online \\
July 7, 2018 \\
\hline Keywords: \\
Supplier selection \\
Multi-agent systems \\
Dyadic collaboration \\
Supply chain dyad \\
Hybrid negotiation protocol \\
Agent negotiation \\
\end{tabular}
\begin{abstract}
A B S T R A C T
This paper proposes a novel form of supplier selection involving the supply chain dyad as the buyer and the suppliers as sellers. The main proposed contribution is a multi-attribute decision hybrid protocol for supplier selection based on collaboration and negotiation, adapted to dyadic collaboration in a supply chain context. Suppliers and the purchasing dyad can reach an agreement on the details of the products simultaneously and exploit the preferences of the customer dyadic partner to enlarge the criteria choices of the products. For this, the proposed protocol combines a one-to-one bilateral dyadic collaboration protocol inside the purchasing dyad along with a one-to-many multi-bilateral bargaining protocol between the purchasing dyad and suppliers. Illustrative multi-agent simulation experiments were carried out to prove the effectiveness of the proposed protocol. The protocol implementation shows better negotiation results than the classic supplier selection process, along with expected higher customer partner satisfaction and a more embedded dyadic relationship.
\end{abstract}

C 2018 by the authors; licensee Growing Science, Canada.

\section{Introduction}

In the 21 st century market, a high-performance supply chain management (SCM) is extremely important in order to maintain competitiveness and excellence. The literature reports two main problems that impact significantly on SCM: supplier selection, and collaboration inside the SC. Collaboration describes how supply chain (SC) organisations work dynamically together and share information to meet particular mutual objectives (Hernández et al., 2011). In the literature, dyadic collaboration refers to a collaboration between two SC organisations. This is the most investigated type of SC collaboration (Harland et al., 2005; Montoya-Torres \& Ortiz-Vargas, 2014).

Supplier selection is a key decision for the buyer (Ghodsypour \& O’Brien, 1998; Narasimhan, 1983). Supplier selection is "finding the right suppliers who are able to provide the buyer with the right quality products and/or services at the right price, at the right time and in the right quantities" (Boran et al., 2009). When interests conflict during a supplier selection procedure, negotiation is necessary to attain

* Corresponding author.

E-mail address: zr.firdaous@gmail.com (F. Zair)

(C) 2019 by the authors; licensee Growing Science, Canada. doi: $10.5267 /$ j.dsl.2018.7.001 
mutual agreement. The buyer defines the product characteristics according to its customer, and the customer requirements indirectly lead the negotiations between the buyer and the suppliers. Therefore, negotiations can be stiff and less profitable. However, is it practical to involve all of the buyer's partners in the negotiations? Obviously, no. A novel business relationships management strategy seems to be required, especially given the actual market trends toward more product customisation. Consequently, frequent interactions with the customer are compelling SCs used to design novel business strategies to increase flexibility and adaptability, and to face the fierce worldwide competition. As Jahani et al. (2015) stated: "unsatisfied customers, information overload and high uncertainty are the main challenges that are faced by today's supply chains". In this sense, relationship-based strategies can be promising. As Emmett and Crocker (2016) argue, rethinking business management according to a more relationship-based approach is likely to be transforming.

In this paper, a novel business strategy based on SC dyadic relationships has been argued as a promising and affordable solution to support mass flexible customisation in future markets within the industry 4.0 context. The proposed strategy is about including the customer company in the procedure of supplier negotiation. We argue that this might be more profitable than the classical method of supplier selection; it reduces uncertainty in SC, and in particular, increases customer satisfaction, which is a key leverage in SCs as previously mentioned. The present work verifies this claim by developing and testing a new model of negotiation for the decision support systems of supplier selection involving suppliers and the SC dyad of customer/buyer. The proposed model was developed using the multi-agent systems paradigm, which is widely used for complex systems such as SCs.

Agents are commonly defined as intelligent computer systems capable of autonomous action in order to achieve predefined objectives (Wooldridge \& Jennings, 1995). Agents can work jointly as problem solvers through competition or cooperation to resolve issues that are beyond their individual capabilities (O'Hare et al., 1996). When studying the supplier selection process, agent-based approaches are widely used (Chen et al., 2016; Ghadimi et al., 2018; Jahani et al., 2015; Pourabdollahi et al. , 2017; Valluri \& Croson, 2005; Yang \& Kao, 2009). This paper makes the following main contributions:

- This paper is the first to take into account the customer company in the supplier selection process. Consequently, it goes beyond internal collaboration inside the dyad, considering additional dimensions such as the management of the dyad outside of the connection.

- This paper combines negotiation and collaboration in the same protocol for supplier selection.

- This paper employs agent technology to capture, through coordination, the dynamics of the buyerseller operations, which is a highly significant and challenging issue according to Ghadimi and Heavey (2013). These dynamics are represented by:

(1) The collaboration dynamics of the buyer - seller operations inside the dyad

(2) The negotiation dynamics of buyer- seller interactions between the dyad and the suppliers.

\section{Conceptual model}

The objective of the collaboration-based negotiation protocol is to support, with a multi-agent system paradigm, the negotiation between purchasing SC dyad and suppliers, i.e. between purchasing company and suppliers, in consideration of the dyadic collaboration relationship between the purchasing company and its dyadic SC partner. The terms "buyer-partner" and "customer-partner" have been adopted to represent, respectively, the purchasing company and the SC member that forms a dyad with the purchasing company. The customer partner of the buyer company is involved in the negotiations once the supplier's bids for the products do not meet the buyer's company requirements. 


\subsection{Agent-based architecture}

An agent-based model is conceptualized to implement the presented protocol. Fig. 1 shows the agentbased architecture of the general supplier selection model supporting dyadic SC collaboration. The general model includes three layers: an agent layer gathering software agents running the system, a techniques layer representing methods agents use to run the system, and a data-resources layer that include the knowledge databases necessary for the system to run. The general supplier selection process is implemented through three stages: a pre-selection phase where potential suppliers are selected among the interested suppliers, a negotiation phase where the buyer negotiate with potential suppliers to identify competitive offers, and a final selection phase where final suppliers are chosen among potential suppliers. The negotiation phase is the phase developed in this paper. The multi-lateral bargaining shown Fig. 1 will be developed in next sections. Five types of agents represent various parties and functions involving in the buyer-seller negotiation process. In the presented model, the buyer represents the buyer dyad, i.e. the customer-partner agent and the buyer-partner agent. The seller represents suppliers. Table 1 shows the types of agents involved and their respective functions.

\section{Table 1}

Agent types in the proposed model

\begin{tabular}{|c|c|c|}
\hline Agent & Abbreviation & Functions \\
\hline Dyad Agent & $\mathrm{DA}$ & Determines required products \\
\hline $\begin{array}{l}\text { Dyad Pre-Selection } \\
\text { Agent }\end{array}$ & DPSA & Control the interactions of agents involving the negotiation model \\
\hline $\begin{array}{l}\text { Dyad Knowledge } \\
\text { Management Agent }\end{array}$ & DKMA & $\begin{array}{l}\text { Accepts the knowledge of required products request from the BPA (respectively the CPA), and } \\
\text { informs the requested knowledge of required products to the BPA (respectively the CPA) }\end{array}$ \\
\hline Buyer Partner Agent & BPA & $\begin{array}{l}\text { - Create instances of the BPNAs for all the suppliers (SAs). } \\
\text { - Configure negotiation strategies of the BPNAs for different suppliers and different } \\
\text { products. } \\
\text { - Control the multi-bilateral bargaining between the BPNAs and the SAs. } \\
\text { - Select cooperative suppliers for products based on the negotiation results between the } \\
\text { BPNAs and the SAs. }\end{array}$ \\
\hline $\begin{array}{l}\text { Customer Partner } \\
\text { Agent }\end{array}$ & BPNA & $\begin{array}{l}\text { Represents the purchasing company and conduct the bilateral bargaining with the corresponding } \\
\text { SA and the bilateral collaboration with the corresponding CPNA }\end{array}$ \\
\hline $\begin{array}{l}\text { Customer Partner } \\
\text { Negotiation Agent }\end{array}$ & $\mathrm{CPA}$ & $\begin{array}{l}\text { - Create instances of the CPNAs for all the suppliers (SAs). } \\
\text { - Configure collaboration strategies of the CPNAs for all the BPNAs. } \\
\text { - } \quad \text { Control the multi-bilateral collaboration between the CPNAs and the BPNAs }\end{array}$ \\
\hline $\begin{array}{l}\text { Buyer Partner } \\
\text { Negotiation Agent }\end{array}$ & CPNA & $\begin{array}{l}\text { Represents the dyadic partner of the purchasing company and conduct the bilateral collaboration } \\
\text { with the corresponding BPNA }\end{array}$ \\
\hline Seller Agent & SA & Represents supplier and conduct the bilateral bargaining with the corresponding BPNA \\
\hline
\end{tabular}

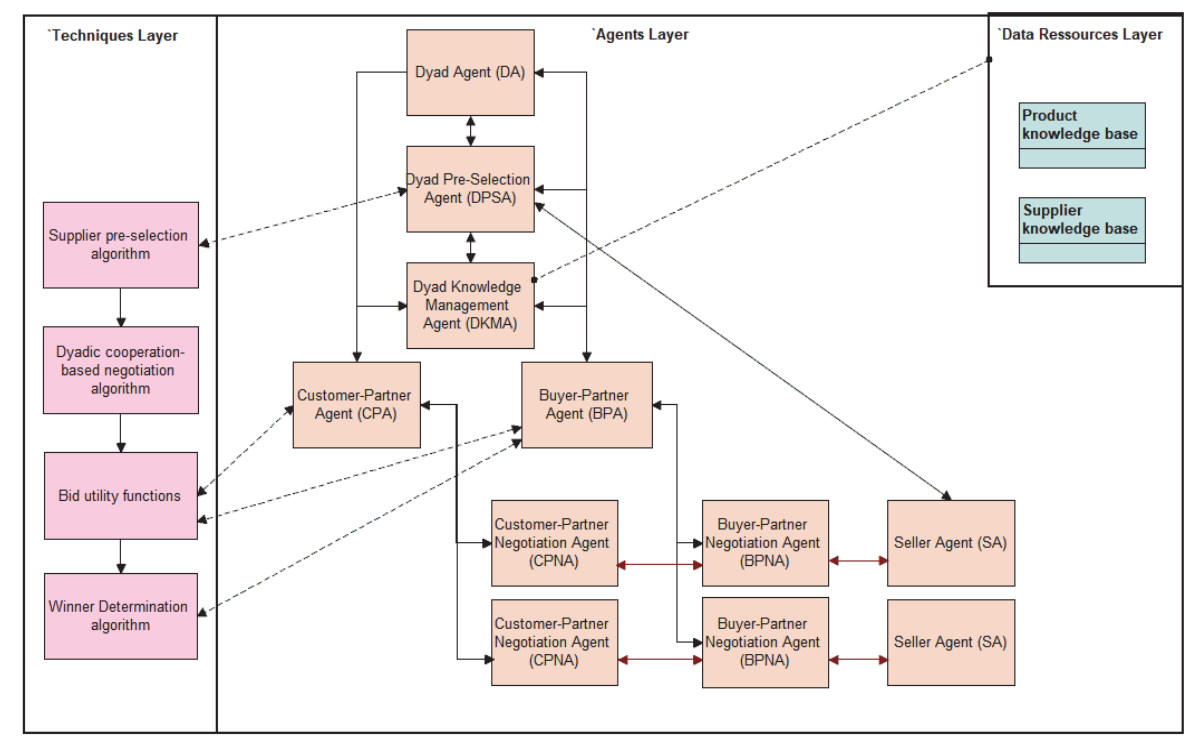

Fig. 1. Agent-based architecture of the proposed model 


\subsection{Agent States and State Semantics}

What follows describes the states and state semantics for each agent involved in the studied process, i.e. the negotiation-based final selection sub-model.

\subsubsection{Dyad Agent}

The concrete states and semantics of the DA are displayed in Fig. 2 and Table 2, respectively.

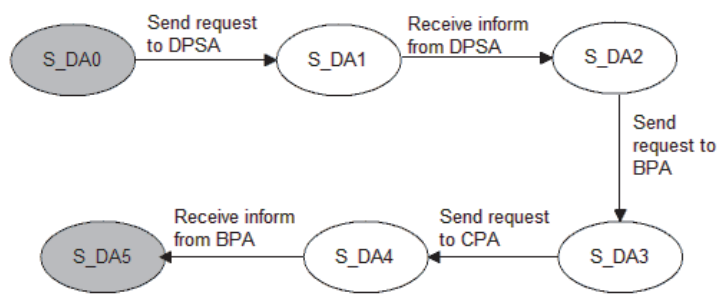

Fig. 2. State transition diagram of the DA

\section{Table 2}

The DA's states and their semantics

\begin{tabular}{ll}
\hline State & Semantic \\
\hline S DA0 & Initial state \\
S_DA1 & The pre-selection request is sent to the DPSA \\
S_DA2 & The pre-selection results are received from the DPSA \\
S_DA3 & The final selection request is sent to the BPA \\
S_DA4 & The final selection request is sent to the CPA \\
S_DA5 & The final selection results are received from the BPA \\
\hline
\end{tabular}

\subsubsection{Dyad Knowledge Management Agent}

Suppliers can propose multiple bids, a bid for each product. The concrete states and semantics of the DKMA are displayed in Fig. 3 and Table 3, respectively.

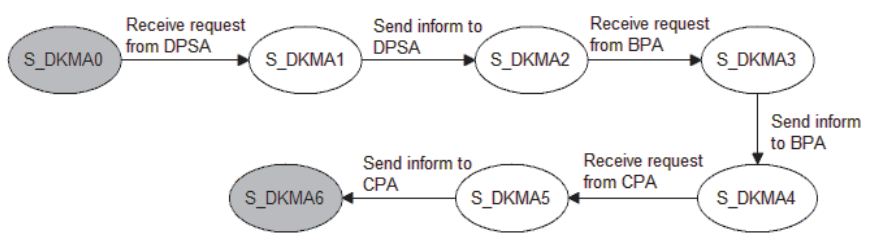

Fig. 3. State transition diagram of the DKMA

Table 3

The DKMA's states, their semantics and roles

\begin{tabular}{|c|c|c|}
\hline State & Semantic & Role \\
\hline S_DKMA 0 & Initial state & \\
\hline S_DKMA 1 & $\begin{array}{l}\text { The supplier knowledge request is received from } \\
\text { the DPSA }\end{array}$ & $\begin{array}{l}\text { Receive request from the DPSA, and inform } \\
\text { interested suppliers' performances on product }\end{array}$ \\
\hline S DKMA 2 & The knowledge of suppliers is sent to the DPSA & transaction capacities to the DPSA \\
\hline S_DKMA 3 & $\begin{array}{l}\text { The knowledge of products request is received } \\
\text { from the BPA }\end{array}$ & $\begin{array}{l}\text { Receive the request from the BPA and inform the } \\
\text { knowledge of products to the BPA }\end{array}$ \\
\hline S_DKMA 4 & The knowledge of products is sent to the BPA & \\
\hline S_DKMA 5 & $\begin{array}{l}\text { The knowledge of products (involving the } \mathrm{CP} \text { ) } \\
\text { request is received from the CPA }\end{array}$ & $\begin{array}{l}\text { Receive the request from CPA and inform the } \\
\text { knowledge of products involving the CP to the }\end{array}$ \\
\hline S_DKMA 6 & $\begin{array}{l}\text { The knowledge of products (involving the } \mathrm{CP} \text { ) is } \\
\text { sent to the CPA }\end{array}$ & CPA \\
\hline
\end{tabular}




\subsubsection{Buyer-Partner Agent}

In order that the customer-partner enters supplier selection process, state S_BPA5 is incorporated to send the necessary information for CPA to create collaboration agents CPNA. After negotiation, a winner determination algorithm is used in the state S_BPA7 to select the final suppliers. The concrete states and semantics of the BPA are displayed in Fig. 4 and Table 4, respectively.

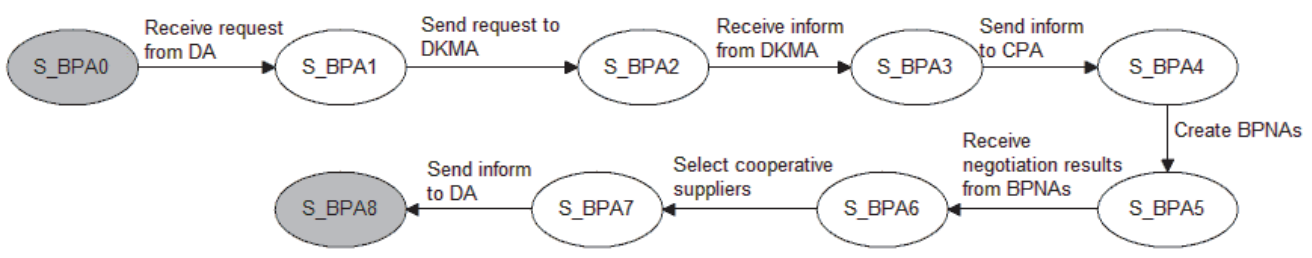

Fig. 4. State transition diagram of the BPA

\section{Table 4}

The BPA's states and their semantics

\begin{tabular}{ll}
\hline State & Semantic \\
\hline S BPA 0 & Initial state \\
S_BPA 1 & The final selection request is received from the DA \\
S_BPA 2 & The product knowledge request is sent to the DKMA \\
S_BPA 3 & The knowledge of products is received from the DKMA \\
S_BPA 4 & The BPNAs for all potential suppliers (SAs) are created \\
S_BPA 5 & The information about the number of potential suppliers (SAs) is sent to the CPA \\
S_BPA 6 & The negotiation results are received from all the BPNAs \\
S_BPA 7 & The cooperative suppliers are selected \\
S_BPA 8 & The final selection results are sent to the DA \\
\hline
\end{tabular}

\subsubsection{Customer-Partner Agent}

To create collaboration agents CPNA for the collaboration-based negotiation, state S_CPA4 is incorporated to obtain the knowledge of the number of negotiating suppliers. The concrete states and semantics of the CPA are displayed in Fig. 5 and Table 5, respectively.

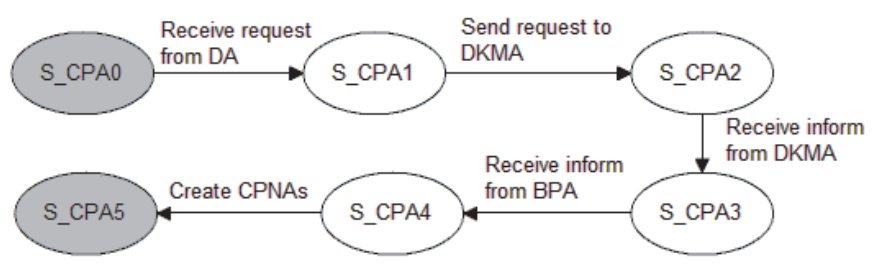

Fig. 5. State transition diagram of the BPA

\section{Table 5}

The CPA's states and their semantics

\begin{tabular}{ll}
\hline State & Semantic \\
\hline S_CPA 0 & Initial state \\
S_CPA 1 & The final selection request is received from the DA \\
S_CPA 2 & The product knowledge request is sent to the DKMA \\
S_CPA 3 & The knowledge of products is received from the DKMA \\
S_CPA 4 & $\begin{array}{l}\text { The information about the number of potential suppliers (SAs) is received } \\
\text { from the BPA }\end{array}$ \\
S_CPA 5 & The CPNAs for all potential suppliers (SAs) are created \\
\hline
\end{tabular}




\subsubsection{Buyer-Partner Negotiation Agent}

S_BPNA2 uses bid utility functions to evaluate the proposal received from SA. If BPNA does not accept the received proposal, S_BPNA2 submits the supplier proposal to CPNA including just the negotiation issues interesting the customer-partner. The concrete states and semantics of the BPNA are displayed in Fig. 6 and Table 6, respectively.

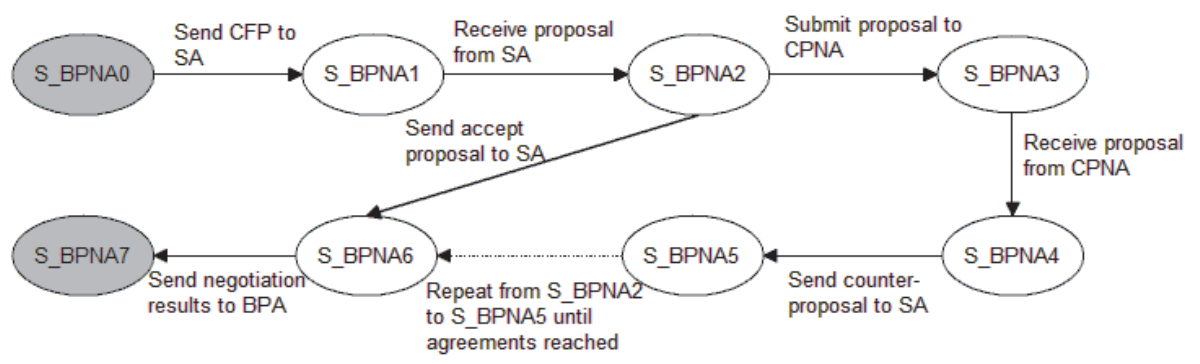

Fig. 6. State transition diagram of the BPNA

Table 6

The BPNA's states and their semantics

\begin{tabular}{ll}
\hline State & Semantic \\
\hline S_BPNA0 & Initial state \\
S_BPNA1 & The CFP is sent to the SA \\
S_BPNA2 & The proposal is received from SA \\
S_BPNA3 & The proposal is submitted to CPNA \\
S_BPNA4 & The proposal is received from CPNA \\
S_BPNA5 & The counter-proposal is sent to SA \\
S_BPNA6 & $\begin{array}{l}\text { The negotiation agreements are reached, namely, the acceptable proposal is } \\
\text { received from or sent to the SA }\end{array}$ \\
S_BPNA7 & The negotiation results are sent to the BPA \\
\hline
\end{tabular}

\subsubsection{Customer-Partner Negotiation Agent}

S_CPNA uses utility functions to evaluate the proposal received from BPNA and uses counter-proposal functions to generate the counter-proposal to be sent to BPNA. The concrete states and semantics of the CPNA are displayed in Fig. 7 and Table 7, respectively.

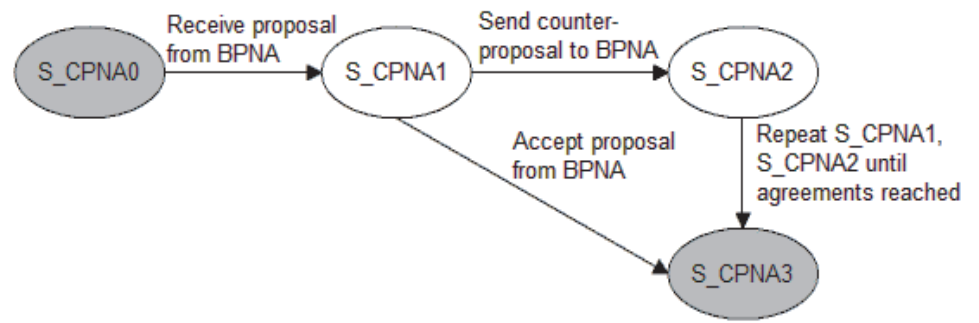

Fig. 7. State transition diagram of the CPNA

Table 7

The CPNA's states and their semantics

\begin{tabular}{ll}
\hline State & Semantic \\
\hline S_CPNA0 & Initial state \\
S_CPNA1 & The proposal is received from BPNA \\
S_CPNA2 & The counter-proposal is sent to BPNA \\
S_CPNA3 & $\begin{array}{l}\text { The negotiation agreements are reached, namely, the acceptable proposal } \\
\text { is received from or sent to the BPNA }\end{array}$ \\
\hline
\end{tabular}




\subsubsection{Seller Agent (SA)}

The proposal and counter-proposal proposed in states S_SA4 and S_SA6 are composed of multiple bids with different products. The concrete states and semantics of the SA are displayed in Fig. 8 and Table 8, respectively.

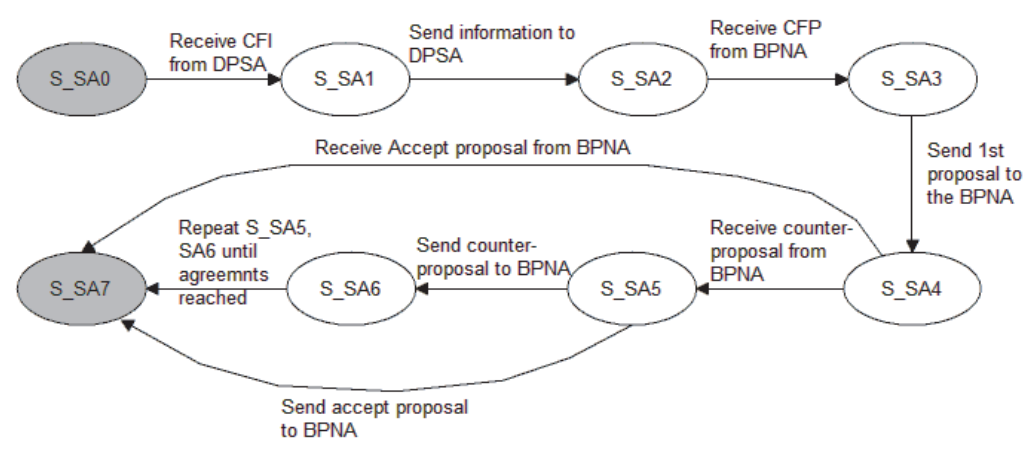

Fig. 8. State transition diagram of the SA

\section{Table 8}

The SA's states and their semantics

\begin{tabular}{ll}
\hline State & Semantic \\
\hline S_SA0 & Initial state \\
S_SA1 & The CFI is received from the DPSA \\
S_SA2 & The information of interested suppliers is sent to the DPSA \\
S_SA3 & The CFP is received from the BPNA \\
S_SA4 & The 1st proposal is sent to the BPNA \\
S_SA5 & The counter-proposal is received from the BPNA \\
S_SA6 & The counter-proposal is sent to the BPNA \\
S_SA7 & $\begin{array}{l}\text { The negotiation agreements are reached, namely, the acceptable proposal is received } \\
\text { from or sent to the BPNA }\end{array}$
\end{tabular}

\subsection{Proposed protocol}

The collaboration-based negotiation protocol presented in this paper is a hybrid protocol composed of two levels as shown in Fig. 9:

- The multi-bilateral bargaining level: governs the multi-bilateral bargaining between the BPNAs and the SAs, which represent the one-to-many negotiation between the dyadic buyer-partner and the suppliers.

- The bilateral collaboration level: supports the bilateral collaboration between the BPA and the CPA, hence supports the multi-bilateral collaboration between the BPNAs and the CPNAs, which represents multiple one-to-one collaboration within the purchasing dyad.

The protocol governing the multi-round bilateral bargaining between the purchasing dyad and potential suppliers is depicted in Figure 10 as follows. Initially, the DA requests the CPA and the BPA to start the negotiation process. The BPA determines the number of suppliers (SAs), informs the CPA of the number of SAs, creates instances of the BPNA for all suppliers (SAs), and waits for the negotiation results between the BPNAs and the SAs. The CPA creates instances of the CPNA for all SAs. In each negotiation round between CPNA, BPNA and SA, the SA acting as a proposer makes multiple bids (one bid for each product) to the opponent BPNA, who acts as a responder. If BPNA accepts the bids, BPNA does not generate new bids. Otherwise, BPNA generates counter-bids. In this last case, BPNA 
creates for CPNA a proposal composed of elements having a new form similar to bids, we refer to as pro. Each pro is created by removing from the bid the negotiation issues that do not match the negotiation issues of CPNA. If CPNA accepts the pro, CPNA does not generate new pro. Otherwise, CPNA generates a counter-proposal. In both cases, CPNA transmits the proposal to BPNA. BPNA adds to the content of the bids the negotiation issues removed earlier (i.e. negotiation issues that do not match the negotiation issues of CPNA) and send the bids to SA. If SA accepts the bids, the negotiation ends; otherwise, SA and BPNA exchange their roles and the negotiation proceeds to the next round. Such iterations continue until an agreement or the negotiation deadline is reached.

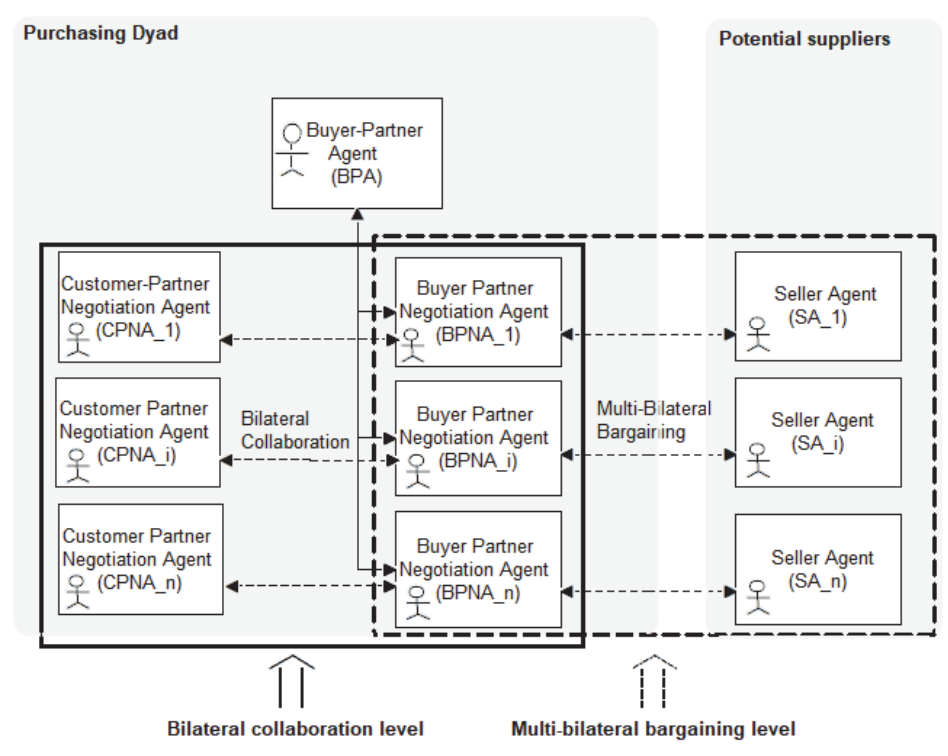

Fig. 9. Hybrid protocol of the proposed model

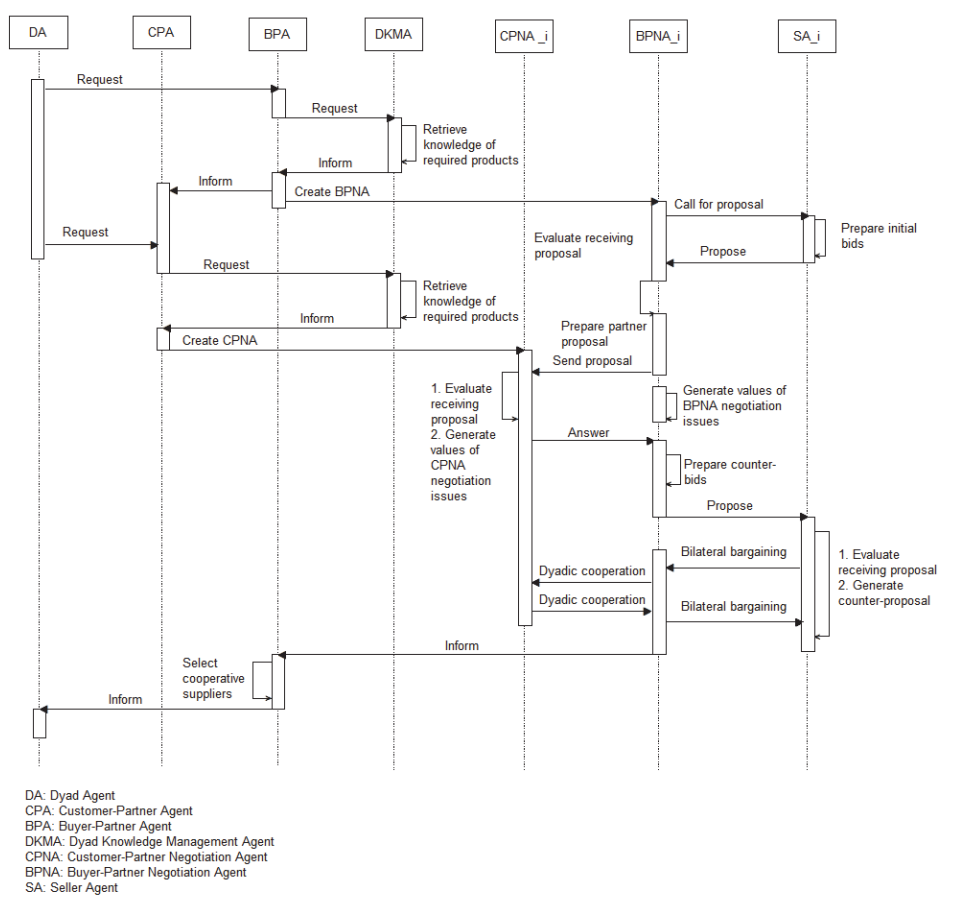

Fig. 10. Protocol diagram of information flow 


\subsection{Procedure of bargaining}

The multi-bilateral collaboration-based bargaining is conducted by the instances of the BPNA and the corresponding instances of the SA and CPNA which make decisions according to their own strategies. Fig. 11 shows the bargaining procedure between illustrative agent instances CPNA, BPNA and SA.

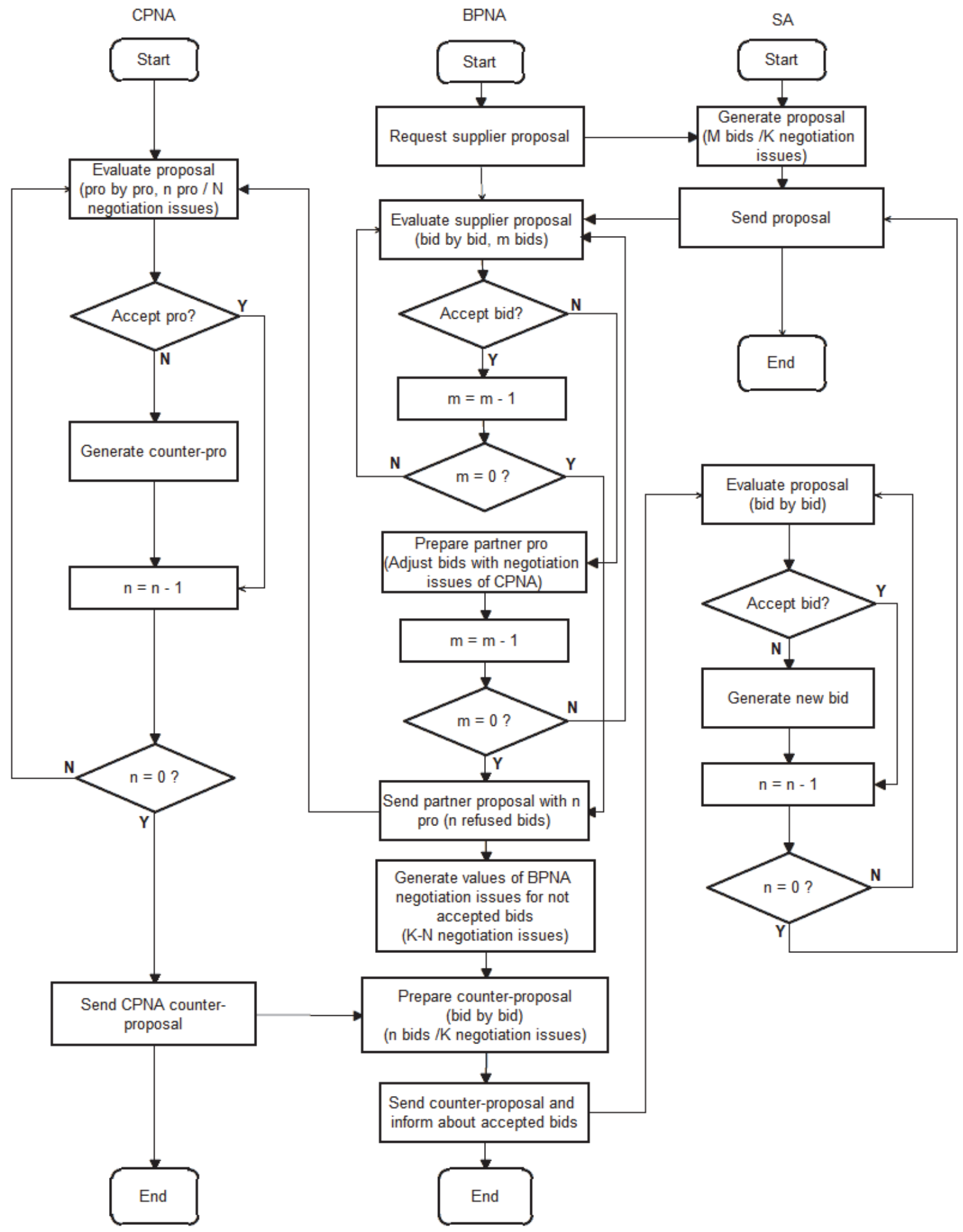

Fig. 11. Bilateral bargaining between a CPNA, a BPNA and a SA 


\section{Computational elements in the proposed protocol}

This section explains how the bargaining agents receive and evaluate the proposals of their partners and how they negotiate and respond according to the negotiation strategies they adopt. The notations used in the negotiation model are summarized in Table 9.

\section{Table 9}

Notations in the proposed protocol

\begin{tabular}{|c|c|}
\hline Notations & Illustrations \\
\hline $\operatorname{prod}_{\mathbf{i}}$ & The product number $\mathbf{i}$ \\
\hline bid $_{\mathbf{i}}$ & The bid of prodi $_{\mathbf{i}}$ \\
\hline pro $_{\mathbf{i}}$ & The pro of prodi $_{\mathbf{i}}$ \\
\hline M & The number of products \\
\hline $\mathbf{I}_{\mathbf{k}}$ & The $\mathbf{k}^{\text {th }}$ dyadic negotiation issue value \\
\hline$\widetilde{I_{k}}$ & The triangular fuzzy number for qualitative $\mathbf{I}_{\mathbf{k}}$ \\
\hline $\mathbf{I}_{\text {kmax }}$ & The $\mathbf{k}^{\text {th }}$ negotiation issue maximum value \\
\hline $\mathbf{I}_{\text {kmin }}$ & The $\mathbf{k}^{\text {th }}$ negotiation issue minimum value \\
\hline $\mathbf{K}$ & The number of negotiation issues \\
\hline $\mathbf{J}_{\mathbf{n}}$ & The $\mathbf{n}^{\text {th }}$ CPNA negotiation issue value, for $\mathrm{k}<=\mathrm{N}$ : $\mathrm{I}_{\mathrm{k}}=\mathrm{J}_{\mathrm{n}}$ \\
\hline $\mathbf{N}$ & The number of negotiation issues influenced by CPNA, $\mathbf{N} \leq \mathbf{K}$ \\
\hline $\mathbf{V}\left(\boldsymbol{I}_{\boldsymbol{k}}\right)$ & The utility function of quantitative $\mathbf{k}^{\text {th }}$ dyadic negotiation issue \\
\hline$V\left(\check{I}_{k}\right)$ & The utility function of qualitative $\mathbf{k}^{\text {th }}$ dyadic negotiation issue \\
\hline $\mathbf{V}\left(J_{n}\right)$ & The utility function of quantitative $\mathbf{n}^{\text {th }}$ CPNA negotiation issue \\
\hline$V\left(\tilde{J_{k}}\right)$ & The utility function of qualitative $\mathbf{n}^{\text {th }}$ CPNA negotiation issue \\
\hline $\mathbf{W}_{\mathbf{k}}$ & The dyadic weight of the $\boldsymbol{k}^{\text {th }}$ negotiation issue \\
\hline$\Omega_{n}$ & The CPNA weight of the $\mathbf{n}^{\text {th }}$ negotiation issue \\
\hline $\mathbf{U}\left(\mathbf{B i d}_{\mathbf{i}}\right)$ & The Bid $_{\mathbf{i}}$ utility function \\
\hline $\mathbf{U}\left(\right.$ pro $\left._{\mathbf{i}}\right)$ & The proi utility function \\
\hline $\mathbf{U R}(\mathbf{t})$ & The reservation utility of an agent in round $\mathbf{t}$ \\
\hline $\mathbf{T}$ & The negotiation deadline of the agent \\
\hline ru & The ultimate reservation utility of the agent \\
\hline $\boldsymbol{\beta}$ & The conceding strategy \\
\hline
\end{tabular}

\subsection{Evaluation Function}

Multiple criteria are involved to evaluate the bids submitted by suppliers. They are in the form of quantitative criteria (price, delivery) or qualitative criteria (quality, service). These criteria represent negotiation issues. To evaluate proposals, it was necessary to use theories of multi-attribute decision making given that several criteria are involved in a bid. In this model, the Multi Attribute Utility Theory (MAUT) method is used as a basis for the evaluation function (Schäfer, 2001).

\subsubsection{Bid/Pro representation}

A bid is composed of product identification and the corresponding details of the products as shown in Table 10. If BPNA refuses the bid offered by the supplier, BPNA sends CPNA a Pro. Unlike the bid which includes all of the negotiation issues, the Pro includes just the negotiation issues that concern the customer (i.e. the dyadic partner). For example, let us consider that the negotiation issues for the buyer company are quality, quantity and service, and that the negotiation issues that involve the dyadic partner of the buyer company are quality and quantity only, being the negotiation issue service involving only the buyer company. In this case, the bid, which is circulating between the buyer company BPNA and suppliers, will include all negotiation issues, i.e. quality, quantity and service. However, the Pro, which 
is circulating between the dyadic partner CPNA and the buyer company BPNA, will include only the negotiation issues with respect to the dyadic partner, i.e. quality and quantity. Table 10 shows the difference between Bid and Pro with respect to the content of each.

\section{Table 10}

Bid and Pro representations

\begin{tabular}{|c|c|c|c|}
\hline Bid/ Pro & Components & Representation & Example \\
\hline Bid & $\begin{array}{l}\text { The products } \\
\text { identification: } \text { Prod }_{\mathrm{i}} \text {. } \\
\text { The values of the } \\
\text { negotiation issues for } \\
\text { each product, noted by } \mathrm{I}_{\mathrm{k}} \\
\text { with respect to bids. }\end{array}$ & $\begin{array}{l}\operatorname{Bid}_{\mathrm{i}}=\left\{\left(\operatorname{Prod}_{1}, \mathrm{I}_{1}, \ldots, \mathrm{I}_{\mathrm{k}}, \ldots, \mathrm{I}_{\mathrm{K}}\right)\right. \\
\left(\operatorname{Prod}_{2}, \mathrm{I}_{1}, \ldots, \mathrm{I}_{\mathrm{k}}, \ldots, \mathrm{I}_{\mathrm{K}}\right), \ldots,\left(\operatorname{Prod}_{\mathrm{i}}, \mathrm{I}_{1},\right. \\
\left.\left.\ldots, \mathrm{I}_{\mathrm{k}}, \ldots, \mathrm{I}_{\mathrm{K}}\right)\right\}\end{array}$ & $\begin{array}{l}\text { Let us consider as example: } \\
\text { - Two products for supply: Prod } 1 \\
\text { and Prod }{ }_{2} \text {. } \\
\text { - Four negotiation issues (hence } \\
\text { k=4): price } \mathrm{I}_{1}, \text { quality } \mathrm{I}_{2} \text {, } \\
\text { delivery } \mathrm{I}_{3}, \text { service } \mathrm{I}_{4} \text {. } \\
\text { Bid }_{1}=\left\{\left(\operatorname{Prod}_{1}, \mathrm{I}_{1}, \mathrm{I}_{2}, \mathrm{I}_{3}, \mathrm{I}_{4}\right),\left(\operatorname{Prod}_{2} \text {, }\right.\right. \\
\left.\left.\mathrm{I}_{1}, \mathrm{I}_{2}, \mathrm{I}_{3}, \mathrm{I}_{4}\right)\right\}= \\
\left\{\left(\operatorname{Prod}_{1}, 550, \mathrm{VG}, 10, \mathrm{M}\right),\left(\operatorname{Prod}_{2} \text {, }\right.\right. \\
500, \mathrm{P}, 11, \mathrm{VG})\} \\
\text { i.e. for product } 1 \text { for example, the } \\
\text { bidder provides product Prod }, \text { and } \\
\text { places a total price } 550, \text { very good } \\
\text { quality, } 10 \text { days delivery and } \\
\text { medium service. }\end{array}$ \\
\hline Pro & $\begin{array}{l}\text { The product } \\
\text { identification: Pro }{ }_{\mathrm{i}} \\
\text { The values of the } \mathrm{N} \\
\text { negotiation issues for } \\
\text { each product. These } \mathrm{N} \\
\text { negotiation issues are the } \\
\mathrm{N} \text { from } \mathrm{K} \text { negotiation } \\
\text { issues of negotiations that } \\
\text { involve the dyadic } \\
\text { partner. These negotiation } \\
\text { issues related to Pro are } \\
\text { noted by } \mathrm{J}_{\mathrm{n}}\end{array}$ & $\begin{array}{l}\operatorname{Pro}_{i}=\left\{\left(\operatorname{Prod}_{1}, \mathrm{~J}_{1}, \ldots, \mathrm{J}_{\mathrm{n}}, \ldots, \mathrm{J}_{\mathrm{N}}\right),\right. \\
\left(\operatorname{Prod}_{2}, \mathrm{~J}_{1}, \ldots, \mathrm{J}_{\mathrm{n}}, \ldots, \mathrm{J}_{\mathrm{N}}\right), \ldots,\left(\operatorname{Prod}_{\mathrm{i}},\right. \\
\left.\left.\mathrm{J}_{1}, \ldots, \mathrm{J}_{\mathrm{n}}, \ldots, \mathrm{J}_{\mathrm{N}}\right)\right\} \text { and } \mathrm{N}<=\mathrm{K}\end{array}$ & $\begin{array}{l}\text { Considering the same settings for } \\
\text { Bid }_{1} \text { above and considering that } \\
\text { among the four negotiation issues } \\
\text { mentioned three involve the dyadic } \\
\text { partner: price } \mathrm{I}_{1} \text {, quality } \mathrm{I}_{2} \text {, delivery } \\
\mathrm{I}_{3} \text {, while one interests only the buyer } \\
\text { company, which is service } \mathrm{I}_{4} \text {. } \\
\text { Considering this, we have: } \\
\text { Pro }_{1}=\left\{\left(\operatorname{Prod}_{1}, \mathrm{I}_{1}, \mathrm{I}_{2}, \mathrm{I}_{3},-\right),\left(\operatorname{Prod}_{2} \text {, }\right.\right. \\
\left.\left.\mathrm{I}_{1}, \mathrm{I}_{2}, \mathrm{I}_{3},-\right)\right\} \\
\quad=\left\{\left(\operatorname{Prod}_{1}, \mathbf{J}_{1}, \mathbf{J}_{2}, \mathbf{J}_{3}\right),\left(\operatorname{Prod}_{2} \text {, }\right.\right. \\
\left.\left.\mathbf{J}_{1}, \mathbf{J}_{2}, \mathbf{J}_{3}\right)\right\} \\
\quad=\left\{\left(\operatorname{Prod}_{1}, 550, \mathrm{VG}, 10\right) \text {, }\right. \\
\left.\left(\operatorname{Prod}_{2}, 500, \mathrm{P}, 11\right)\right\} \\
\text { As for the bid, such notation means } \\
\text { that product Prod } \text { for example is }_{10} \text { provided with a total price } 550 \text {, very } \\
\text { good quality and } 10 \text { days delivery. }\end{array}$ \\
\hline
\end{tabular}

\subsubsection{Negotiation issues normalization}

The negotiation issues may take either a qualitative form or a quantitative form. In the proposed utility function, the issues values should be normalized to a $[0,1]$ scale. For quantitative issues which can be decomposed into benefit issues and cost issues, the corresponding numeric values in the $[0,1]$ scale can be obtained by normalized functions. For a benefit issue, the larger the issue value is the better. It can be normalized by Eq. (1). For a cost issue, the smaller the issue value is the better. It can be normalized by Eq. (2).

$$
\begin{aligned}
& V\left(I_{k}\right)=\frac{I_{k}-I_{k m i n}}{I_{k m a x}-I_{k m i n}}, k=1,2 \ldots, K \\
& V\left(I_{k}\right)=\frac{I_{k m a x}-I_{k}}{I_{k m a x}-I_{k m i n}}, \quad k=1,2 \ldots, K
\end{aligned}
$$


For qualitative issues, the agent defines a set of linguistic values $\{\mathrm{VP}, \mathrm{P}, \mathrm{M}, \mathrm{G}, \mathrm{VG}\}$. These five linguistic values and the related numeric values shown in Table 11 are defined based on FST (Mikhailov, 2002). Considering the triangular fuzzy number $\widetilde{I_{k}}=(a, b, c)$, the qualitative issue can then be transformed into the $[0,1]$ scale based on the graded mean integration representation method as shown in Eq. (3) (Chou, 2003).

$$
\mathrm{V}\left(\widetilde{\mathrm{I}_{\mathrm{k}}}\right)=\frac{1}{6}(\mathrm{a}+4 \mathrm{~b}+\mathrm{c}), \mathrm{k}=1,2 \ldots, \mathrm{K}
$$

Table 11

Qualitative negotiation issue information

\begin{tabular}{lll}
\hline State & Semantic & Linguistic values \\
\hline Very good & VG & $(0.75,1,1)$ \\
Good & G & $(0.5,0.75,1)$ \\
Medium & M & $(0.25,0.5,0.75)$ \\
Poor & P & $(0,0.25,0.5)$ \\
Very poor & VP & $(0,0,0.25)$ \\
\hline
\end{tabular}

\subsubsection{Bid/pro utility function}

Researchers usually assume that the multiple issues are independent, hence evaluate bids based on the multi-attribute utility theory (MAUT) (Edwards, 2013). The utility function enables to rank bids by assigning a larger value to more preferred bids rather than less preferred bids. In the proposed model, the utility of a bid proposed by an agent is expressed as the weighted sum of normalized issue values as shown in Eq. (4). Besides, the utility of a pro is expressed as the weighted sum of normalized issue values as shown in Eq. (5).

$$
\begin{aligned}
& \mathrm{U}\left(\operatorname{Bid}_{\mathrm{i}}\right)=\sum_{\mathrm{k}} \mathrm{w}_{\mathrm{k}} \mathrm{V}\left(\mathrm{I}_{\mathrm{k}}\right), \mathrm{k}=1,2 \ldots, \mathrm{K} \\
& \mathrm{U}\left(\mathrm{pro}_{\mathrm{i}}\right)=\sum_{\mathrm{n}} \Omega_{\mathrm{n}} \mathrm{V}\left(\mathrm{J}_{\mathrm{n}}\right), \mathrm{n}=1,2 \ldots, \mathrm{N}
\end{aligned}
$$

\subsection{Negotiation decision function}

In the proposed model, agents negotiate in a competitive form. The negotiation strategies consist of 3 steps: conceding, responding, and proposing (Lai \& Sycara, 2009).

\subsubsection{Conceding function}

In this step the time-dependent strategy (Faratin et al., 1998) is adopted. It is characterized by Eq. (6):

$$
\mathrm{UR}(\mathrm{t})=1-(1-\mathrm{ru})\left(\frac{\mathrm{t}}{\mathbf{T}}\right)^{\frac{1}{\mathbf{\beta}}}
$$

\subsubsection{Responding function}

In this step, the agent determines whether if a bid should be accepted or rejected. If the reservation utility $\mathrm{UR}(\mathrm{t}) \leq \mathrm{U}\left(\mathrm{Bid}_{\mathrm{i}}\right)$ the agent accepts the bid; otherwise, the agent rejects the bid and generates a counter-bid.

\subsubsection{Proposing function}

In this step, the agent generates the counter-bid. According to (Lai \& Sycara, 2009), If, for the negotiator, the larger the issue value is the better, the proposed counter value will be :

- For quantitative issues:

$$
\mathbf{I}_{\mathbf{k}}=\mathbf{I}_{\mathbf{k m i n}}+\mathrm{UR}(\mathrm{t}) \times\left(\mathbf{I}_{\mathbf{k m a x}}-\mathbf{I}_{\mathbf{k m i n}}\right)
$$

- For qualitative issues: 


$$
\begin{array}{lll} 
& \text { VG } & \text { For UR(t) } \epsilon] 0.875 ; 1] \\
\mathbf{I}_{\mathbf{k}}= & \text { For UR(t) } \epsilon] 0.625 ; 0.875] \\
\mathrm{M} & \text { For UR }(\mathrm{t}) \epsilon] 0.375 ; 0.625] \\
\mathrm{P} & \text { For UR(t) } \epsilon] 0.125 ; 0.375] \\
\mathrm{VP} & \text { For UR(t) } \epsilon[0 ; 0.125]
\end{array}
$$

Else

- For quantitative issues

$$
\mathbf{I}_{\mathbf{k}}=\mathbf{I}_{\mathbf{k m a x}}-\mathrm{UR}(\mathrm{t}) \times\left(\mathbf{I}_{\mathbf{k m a x}}-\mathbf{I}_{\mathbf{k m i n}}\right)
$$

- For Qualitative issues:

$$
\begin{aligned}
& \text { VP For UR(t)€ ]0.875;1] } \\
& \left.\left.\mathbf{I}_{\mathbf{k}}=\quad \mathrm{P} \quad \text { For UR(t)€ }\right] 0.625 ; 0.875\right] \\
& \mathrm{M} \quad \text { For } \operatorname{UR}(\mathrm{t}) \epsilon] 0.375 ; 0.625] \\
& \mathrm{G} \quad \text { For } \operatorname{UR}(\mathrm{t}) \epsilon] 0.125 ; 0.375] \\
& \text { VG For UR(t) } \in[0 ; 0.125]
\end{aligned}
$$

\section{Simulation and experimental results}

An example is conducted to illustrate the multi-bilateral collaboration-based bargaining procedure between the CPNAs, the BPNAs and the SAs. We assume that a company (the purchasing company) needs to purchase a set of products $\operatorname{Prod}_{1}, \operatorname{Prod}_{2}$ and $\operatorname{Prod}_{3}$. The negotiation issues are: price, quality, delivery and service, and the first three negotiations issues influence CPNA. This work focuses on the dyadic collaboration and negotiations between the dyad and suppliers. The following case of study illustrates the steps of the negotiation protocol with a supplier. For the sake of comparison, the data used are based on (Yu et al., 2017), a case study from literature developing agent negotiation within a classical supplier selection protocol. To solve this experimental example in a fast-easy manner, we recommend using Java Agent Development Framework (JADE). JADE is a widely used software framework to develop agent applications according to the FIPA specifications.

\subsection{Phase 1: Initialization}

To start the bilateral bargaining, BPNA requests the supplier to send a proposal. The supplier generates an initial proposal (Table12) composed of 3 bids (a bid for each product) and submits it to BPNA. Each bid is composed of the product identification $\left(\operatorname{Prod}_{1}, \operatorname{Prod}_{2}\right.$ or $\left.\operatorname{Prod}_{3}\right)$ and values for the four negotiation issues.

Table 12

Initial bid submitted by the supplier

\begin{tabular}{lllll}
\hline Products & Price & Quality & Delivery & Service \\
\hline Prod $_{1}$ & 650 & VG & 20 & VP \\
Prod $_{2}$ & 850 & VP & 30 & VP \\
Prod $_{3}$ & 1040 & VP & 40 & VP \\
\hline
\end{tabular}

\subsection{Phase 2: BPNA Bids evaluation, conceding and responding phase}

After receiving the bids, BPNA evaluates the proposal bid by bid. First, the agent calculates the bids utility functions based on the BPNA negotiation issue value ranges (see Table 13), then uses Eq. (6) to generate the reservation utility of the round based on parameters shown in Table 14. 
Table 13

BPNA Negotiation issue value ranges \& weight

\begin{tabular}{lllll}
\hline BPNA Parameters & Price & Quality & Delivery & Service \\
\hline Prod $_{1}$ & {$[500,600]$} & VP to VG & 1,10 & VP to VG \\
Prod $_{2}$ & {$[700,800]$} & VP to VG & 1,20 & VP to VG \\
Prod3 $_{3}$ & {$[900,1000]$} & VP to VG & 1,30 & VP to VG \\
Weight & 0,4 & 0,3 & 0,15 & 0,15 \\
\hline
\end{tabular}

Table 14

Conceding parameters

\begin{tabular}{llll}
\hline Agents & Ru & T & $\boldsymbol{\beta}$ \\
\hline BPNA & 0 & 50 & 1 \\
CPNA & 0 & 50 & 5 \\
Supplier & 0 & 50 & 1 \\
\hline
\end{tabular}

In this step the agent determines whether if a bid should be accepted or rejected. If $U R(t) \leq U\left(\operatorname{Bid}_{i}\right)$, the agent accepts the bid; otherwise, the agent rejects it.

Table 15

Round 1: BPNA Conceding and responding

\begin{tabular}{lllllllllll}
\hline Products & Price & $\begin{array}{l}\text { V } \\
\text { (price) }\end{array}$ & Quality & $\begin{array}{l}\text { V } \\
\text { (quality) }\end{array}$ & Delivery & $\begin{array}{l}\text { V } \\
\text { (delivery) }\end{array}$ & Service & $\begin{array}{l}\text { V } \\
\text { (Service) }\end{array}$ & $\begin{array}{l}\text { U } \\
\text { (Bid) }\end{array}$ & Responding \\
\hline Prod 1 & 650 & $-0,5$ & VG & 1 & 20 & $-1,111$ & VP & 0,041 & $-0,073$ & Refused \\
Prod2 & 850 & $-0,5$ & VP & 0,041 & 30 & $-0,526$ & VP & 0,041 & $-0,260$ & Refused \\
Prod 3 & 1040 & $-0,4$ & VP & 0,041 & 40 & $-0,344$ & VP & 0,041 & $-0,192$ & Refused \\
\hline
\end{tabular}

In round 1 , for each $\mathrm{Bid}_{\mathrm{i}}$ we have BPNA $\mathrm{UR}(\mathrm{t})>\mathrm{U}\left(\mathrm{Bid}_{\mathrm{i}}\right)$. Therefore, all the supplier bids are refused (see Table 15). As counter bids are generated in collaboration with CPNA, BPNA sends to CPNA the pro for each bid. The pro includes supplier proposed values with respect to price, quality and delivery.

\subsection{Phase 3: CPNA pro evaluation, conceding, responding and proposing phase}

In turn, CPNA evaluates the received proposal from BPNA based on its negotiation issue value ranges and weights (see Table 16), then calculates its reservation utility using its conceding parameters (see Table 14). Table 17 shows the pro utility function values and the pro acceptance or rejection decision.

Table 16

CPNA negotiation issues value ranges and weights

\begin{tabular}{|c|c|c|c|c|c|}
\hline $\begin{array}{l}\text { CPNA } \\
\text { Parameters }\end{array}$ & $\begin{array}{l}\text { Price } \\
\text { min }\end{array}$ & Price max & Quality & $\begin{array}{l}\text { Delivery } \\
\text { min }\end{array}$ & Delivery max \\
\hline Prod $_{1}$ & 500 & $\begin{array}{l}\text { For Quality = VP, P, M, G: } 600 \\
\text { else (VG): } 700\end{array}$ & VP to $\mathrm{VG}$ & 1 & $\begin{array}{l}\text { For Quality = VP, P, M, G: } 10 \\
\text { else (VG): } 15\end{array}$ \\
\hline $\operatorname{Prod}_{2}$ & 700 & 800 & VP to VG & 1 & 20 \\
\hline $\operatorname{Prod}_{3}$ & 850 & 1000 & $\mathrm{VP}$ to $\mathrm{VG}$ & 1 & $\begin{array}{l}\text { For price }=850,950: 35 \\
\text { else }(\text { price }=900,1000): 1,30\end{array}$ \\
\hline weight & 0.4 & 0.4 & 0.4 & 0.2 & 0.2 \\
\hline
\end{tabular}

Table 17

Round 1: CPNA Conceding and responding

\begin{tabular}{lllllllll}
\hline Products & Price & $\begin{array}{l}\text { V } \\
\text { (price) }\end{array}$ & Quality & $\begin{array}{l}\text { V } \\
\text { (quality) }\end{array}$ & Delivery & $\begin{array}{l}\text { V } \\
\text { (delivery) }\end{array}$ & $\begin{array}{l}\text { U } \\
\text { (Pro) }\end{array}$ & Responding \\
\hline Prod $_{1}$ & 650 & 0,25 & VG & 1 & 20 & $-0,357$ & 0,411 & Accepted \\
Prod $_{2}$ & 850 & $-0,5$ & VP & 0,041 & 30 & $-0,526$ & $-0,288$ & Refused \\
Prod $_{3}$ & 1040 & $-0,266$ & VP & 0,041 & 40 & $-0,344$ & $-0,158$ & Refused \\
\hline
\end{tabular}

In this case, CPNA accepts the pro of Prod $_{1}$. Therefore, the values of the negotiation issues price, quality and delivery of the next counter-bid will not change for this product, and BPNA will generate a value only for the negotiation issue service. For $\operatorname{Prod}_{2}$ and $\operatorname{Prod}_{3}$, pro are refused, therefore a counterpro is generated for each of the two products using Eqs. (7-10). The counter-pro is then sent to BPNA. 
4.4 Phase 4: BPNA proposing phase

After receiving the counter-pro from CPNA, BPNA generates values for the lacking negotiation issues (in this case: Service) to form the counter-proposal. To close round 1, BPNA send the prepared counterproposal to the supplier (see Table 18).

Table 18

Round 2: counter-bids to the supplier by (BPNA and CPNA)

\begin{tabular}{lllll}
\hline Counter Bids & Price & Quality & Delivery & Service \\
\hline Prod $_{1}$ & 650,00 & VG & 20,00 & VG \\
Prod $_{2}$ & 763,10 & P & 12,99 & VG \\
Prod $_{3}$ & 944,64 & P & 22,45 & VG \\
\hline
\end{tabular}

\subsection{Phase 5: Supplier evaluation and decision}

In the same way, the supplier evaluates BPNA counter-proposal bid by bid based on its negotiation parameters (see Table 19 and Table 14) and decides whether it will generate a counter-bid or accept the bid.

\section{Table 19}

Supplier negotiation issue value ranges and weights

\begin{tabular}{lllll}
\hline $\begin{array}{l}\text { Supplier } \\
\text { Parameters }\end{array}$ & Price & Quality & Delivery & Service \\
\hline Prod $_{1}$ & {$[550,650]$} & VP to VG (for price [630,650] just VG is offered) & 5,20 & VP to VG \\
Prod $_{2}$ & {$[750,850]$} & VP to VG & 10,30 & VP to VG \\
Prod $_{3}$ & {$[940,1040]$} & VP to VG & 15,40 & VP to VG \\
weight & 0,4 & 0,3 & 0,15 & 0,15 \\
\hline
\end{tabular}

Table 20

Round 2: Supplier Conceding and responding

\begin{tabular}{lllllllllll}
\hline Products & Price & $\begin{array}{l}\text { V } \\
\text { (price) }\end{array}$ & Quality & $\begin{array}{l}\text { V } \\
\text { (quality) }\end{array}$ & Delivery & $\begin{array}{l}\text { V } \\
\text { (delivery) }\end{array}$ & Service & $\begin{array}{l}\text { V } \\
\text { (Service) }\end{array}$ & $\begin{array}{l}\text { U } \\
\text { (Bid) }\end{array}$ & Responding \\
\hline Prod1 & 650 & 1,00 & VG & 1,00 & 20,00 & 1,00 & VG & 0,04 & 0,86 & Accepted \\
Prod2 & 763,1 & 0,13 & P & 0,75 & 12,99 & 0,15 & VG & 0,04 & 0,31 & Refused \\
Prod3 & 944,64 & 0,05 & P & 0,75 & 22,45 & 0,30 & VG & 0,04 & 0,29 & Refused \\
\hline
\end{tabular}

In round 2, the Supplier $U R(t)<U\left(B d_{1}\right)$ for Prod 1 counter-bid, therefore this bid is accepted. However, for Prod 2 and Prod 3 counter bids the Supplier BPNA UR(t) $>U\left(B_{i d}\right)$, therefore, according to Eq. (6) and Tables $14 \& 20$, these bids are refused, and a new counter-bids are generated by the Supplier for each of the two products and the $3^{\text {rd }}$ round started (Table 21 ).

Table 21

Round 3: counter-bids generated by the Supplier

\begin{tabular}{lllll}
\hline Counter Bids & Price & Quality & Delivery & Service \\
\hline Prod $_{2}$ & 830 & $\mathrm{P}$ & 26 & $\mathrm{P}$ \\
Prod $_{3}$ & 1020 & $\mathrm{P}$ & 35 & $\mathrm{P}$ \\
\hline
\end{tabular}

Agents continue bargaining along the same previous phases until agreements are reached or the negotiation deadline is reached (Table 22).

Table 22

Round 6: Supplier Conceding and responding

\begin{tabular}{lllllllllll}
\hline Products & Price & $\begin{array}{l}\text { V } \\
\text { (price) }\end{array}$ & Quality & $\begin{array}{l}\text { V } \\
\text { (quality) }\end{array}$ & Delivery & $\begin{array}{l}\text { V } \\
\text { (delivery) }\end{array}$ & Service & $\begin{array}{l}\text { V } \\
\text { (Service) }\end{array}$ & $\begin{array}{l}\text { U } \\
\text { (Bid) }\end{array}$ & Responding \\
\hline Prod2 & & 0,37 & P & 0,75 & 17,54 & 0,38 & M & 0,50 & 0,50 & Accepted \\
& 787,06 & & & & & & & & & \\
Prod3 & 980,58 & 0,41 & P & 0,75 & 26,25 & 0,45 & M & 0,50 & 0,53 & Accepted \\
\hline
\end{tabular}

Table 23 shows bargaining interactions between the dyad and the supplier of all rounds. 
Table 23

Results of protocol bargaining interactions

\begin{tabular}{|c|c|c|c|c|c|}
\hline Round & Product & Price & Quality & Delivery & Service \\
\hline 1 & Prod $_{1}$ & 650 & VG & 20 & VP \\
\hline By & $\operatorname{Prod}_{2}$ & 850 & VP & 30 & VP \\
\hline the Supplier & $\operatorname{Prod}_{3}$ & 1040 & VP & 40 & VP \\
\hline 2 & Prod $_{1}$ & 650 & VG & 20 & VG \\
\hline By & $\operatorname{Prod}_{2}$ & 763 & $\mathrm{P}$ & 13 & VG \\
\hline (BPNA+CPNA) & $\operatorname{Prod}_{3}$ & 944,64 & $\mathrm{P}$ & 22,45 & VG \\
\hline 3 & $\operatorname{Prod}_{1}$ & $* * *$ & $* * *$ & $* * *$ & $* * *$ \\
\hline By & $\operatorname{Prod}_{2}$ & 830 & $\mathrm{P}$ & 26 & $P$ \\
\hline the Supplier & $\operatorname{Prod}_{3}$ & 1020 & $\mathrm{P}$ & 35 & $\mathrm{P}$ \\
\hline 4 & Prod $_{1}$ & $* * *$ & $* * *$ & $* * *$ & $* * *$ \\
\hline By & $\operatorname{Prod}_{2}$ & 778 & $\mathrm{P}$ & 16 & G \\
\hline (BPNA+CPNA) & $\operatorname{Prod}_{3}$ & 967 & $\mathrm{P}$ & 23,8 & G \\
\hline 5 & Prod $_{1}$ & $* * *$ & $* * *$ & $* * *$ & $* * *$ \\
\hline By & $\operatorname{Prod}_{2}$ & 810 & $\mathrm{P}$ & 22 & $\mathrm{P}$ \\
\hline the Supplier & $\operatorname{Prod}_{3}$ & 1000 & $\mathrm{P}$ & 30 & $\mathrm{P}$ \\
\hline 6 & $\operatorname{Prod}_{1}$ & $* * *$ & $* * *$ & $* * *$ & $* * *$ \\
\hline By & $\operatorname{Prod}_{2}$ & 787 & $\mathrm{P}$ & 17,54 & M \\
\hline (BPNA+CPNA) & $\operatorname{Prod}_{3}$ & 980,58 & $\mathrm{P}$ & 26,25 & M \\
\hline
\end{tabular}

To validate the effectiveness of the proposed protocol, the above final results of bargaining between the dyad and the supplier have been compared with the bargaining results of the classical supplier selection protocol (Yu et al., 2017), whose data was used to compute the present experimental example. As mentioned earlier, this work has been selected from the literature as a representative example of a quality classic negotiation protocol involving the same modelling components as our system except for the dyadic partner of the purchasing company. Therefore, compared to (Yu et al., 2017) as shown in Fig. 12, it was found that utility of the proposed protocol is greater than the utility within the classic negotiation protocol.

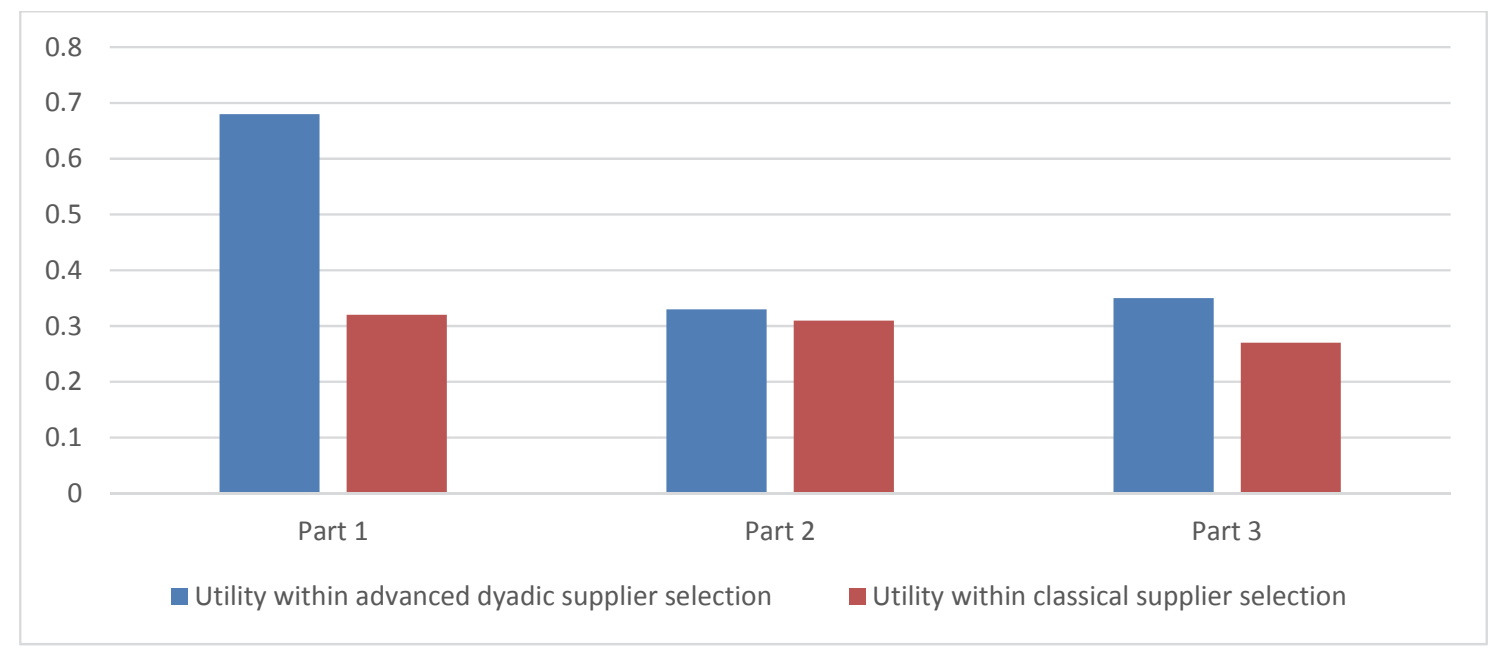

Fig. 12. Utility comparison between the proposed dyadic negotiation protocol and a classical negotiation protocol for supplier selection

\section{Discussion and conclusion}

In this paper, a hybrid advanced negotiation protocol for supplier selection integrating collaboration with the customer of the purchasing company has been developed. Suppliers and the purchasing dyad (formed of the purchasing company and its customer) can reach an agreement on the details of the products simultaneously and exploit the preferences of the customer to enlarge the criteria choices of the products. Based on this, the proposed model is unique and more realistic than that proposed in previous studies. With the help of this model, the procurement departments of enterprises can select 
optimal suppliers simultaneously and enterprises that make full use of the data, statistics and expertise of their customer partner in the supplier selection environment to release the criteria values of required products during negotiation while overcoming privacy issues. Consequently, this protocol opens during negotiation further trading opportunities about the required products, which opens up avenues for reducing cost, increasing quality, and generally enhancing the value of the negotiation issues. This increases SC agility and enhances customer satisfaction. Furthermore, engaging the customer partner in the supplier selection process is expected to develop loyalty inside the dyadic relationship, which will embed more of the existing trust and the collaboration basis of the SC. This affects the problem of multi-tier information sharing through the SC. Indeed, recent research ( Soosay \& Hyland, 2015; Kembro \& Selviaridis, 2015) suggests the release of multi-tier information sharing trust blockage in SCs by implementing collaboration between the SC dyads. The proposed protocol is expected to facilitate the resolution context of dyad-dyad multi-tier information sharing given that the modelling unity used in the present work is the SC dyad, and additionally given that the information within the proposed protocol is shared without further trust sacrifices or serious privacy compromises from the stakeholders.

There are several research avenues for further research. First, in the proposed model, the preferences of the decision makers have been stated by assigned parameters in advance. In future, it is recommended to expand the intelligence and automation of the collaboration-based negotiation protocol and to allow the agents to dynamically select the negotiation strategies to best represent the stakeholders' preferences to do with the products. Second, further work can be conducted to extend the proposed protocol to additional SC issues and dyad management issues other than supplier selection such as resource allocation, B2C e-commerce order fulfilment. Finally, the proposed protocol should be applied to real industrial case studies to further validate its efficiency. Practically, the decision support system suggested in this paper fits many real-world applications once the concerned environment involves changing markets, customization and a degree of uncertainty. For example, a useful real-world application is strategic resource allocation in e-business SC. How? For example, in B2C, where e-retailers offer a selection of customised services to the final customers, e-retailers need several resources such as payment companies, suppliers, logistic providers, etc. Applied to the proposed model in the present work, each resource may represent a supplier. Therefore, the proposed model can be applied for each resource and each negotiation process with respect to a given resource, which has its own negotiation issues. The functionality of the whole system relies on the fact that the outputs obtained from the different models (i.e. a model for each resource) represents, along with the coming orders, input for operational models of B2C resource allocation such as Yao (2017) and Zair et al. (2018). In the same pattern, another useful real-world application is cross-docking. Applied to the proposed model, the SC supplier represents the dyadic partner in our model, the e-marketplace represents the buyer company, and the transport provider represents the supplier.

\section{References}

Boran, F. E., Genç, S., Kurt, M., \& Akay, D. (2009). A multi-criteria intuitionistic fuzzy group decision making for supplier selection with TOPSIS method. Expert Systems with Applications, 36(8), 11363-11368.

Chen, S., Tai, K., \& Li, Z. (2016). Evaluation of supply chain resilience enhancement with multi-tier supplier selection policy using agent-based modeling. In 2016 IEEE International Conference on Industrial Engineering and Engineering Management (IEEM) (pp. 124-128).

Chou, C.-C. (2003). The canonical representation of multiplication operation on triangular fuzzy numbers. Computers \& Mathematics with Applications, 45(10-11), 1601-1610.

Soosay, C. A., \& Hyland, P. (2015). A decade of supply chain collaboration and directions for future research. Supply Chain Management: An International Journal, 20(6), 613-630.

Edwards, W. (2013). Utility theories: Measurements and applications (Vol. 3). Springer Science \& Business Media.

Emmett, S., \& Crocker, B. (2016). The Relationship-Driven Supply Chain: Creating a Culture of Collaboration Throughout the Chain. CRC Press. 
Faratin, P., Sierra, C., \& Jennings, N. R. (1998). Negotiation decision functions for autonomous agents. Robotics and Autonomous Systems, 24(3-4), 159-182.

Ghadimi, P., Ghassemi Toosi, F., \& Heavey, C. (2018). A multi-agent systems approach for sustainable supplier selection and order allocation in a partnership supply chain. European Journal of Operational Research, 269(1), 286-301. https://doi.org/10.1016/j.ejor.2017.07.014

Ghadimi, P., \& Heavey, C. (2013). A Review of Applications of Agent-Based Modelling and Simulation in Supplier Selection Problem (pp. 101-107). IEEE.

Ghodsypour, S. H., \& O’Brien, C. (1998). A decision support system for supplier selection using an integrated analytic hierarchy process and linear programming. International Journal of Production Economics, 56, 199212.

Harland, C., Knight, L., Lamming, R., \& Walker, H. (2005). Outsourcing: assessing the risks and benefits for organisations, sectors and nations. International Journal of Operations \& Production Management, 25(9), $831-850$.

Hernández, J. E., Poler, R., Mula, J., \& Lario, F. C. (2011). The Reverse Logistic Process of an Automobile Supply Chain Network Supported by a Collaborative Decision-Making Model. Group Decision and Negotiation, 20(1), 79-114.

Jahani, A., Azmi Murad, M. A., bin Sulaiman, M. N., \& Selamat, M. H. (2015). An agent-based supplier selection framework: Fuzzy case-based reasoning perspective. Strategic Outsourcing: An International Journal, 8(2/3), 180-205.

Kembro, J., \& Selviaridis, K. (2015). Exploring information sharing in the extended supply chain: an interdependence perspective. Supply Chain Management: An International Journal, 20(4), 455-470.

Lai, G., \& Sycara, K. (2009). A generic framework for automated multi-attribute negotiation. Group Decision and Negotiation, 18(2), 169.

Mikhailov, L. (2002). Fuzzy analytical approach to partnership selection in formation of virtual enterprises. Omega, 30(5), 393-401.

Montoya-Torres, J. R., \& Ortiz-Vargas, D. A. (2014). Collaboration and information sharing in dyadic supply chains: A literature review over the period 2000-2012. Estudios Gerenciales, 30(133), 343-354.

Narasimhan, R. (1983). An analytical approach to supplier selection. Journal of Supply Chain Management, 19(4), 27-32.

O’Hare, G. M. P., Jennings, N. R., \& Jennings, N. (1996). Foundations of Distributed Artificial Intelligence. John Wiley \& Sons.

Pourabdollahi, Z., Karimi, B., Mohammadian, K., \& Kawamura, K. (2017). A hybrid agent-based computational economics and optimization approach for supplier selection problem. International Journal of Transportation Science and Technology, 6(4), 344-355.

Schäfer, R. (2001). Rules for using multi-attribute utility theory for estimating a user's interests. In Ninth Workshop Adaptivität und Benutzermodellierung in Interaktiven Softwaresystemen (pp. 8-10).

Valluri, A., \& Croson, D. C. (2005). Agent learning in supplier selection models. Decision Support Systems, 39(2), 219-240.

Wooldridge, M., \& Jennings, N. R. (1995). Agent theories, architectures, and languages: A survey. In M. J. Wooldridge \& N. R. Jennings (Eds.), Intelligent Agents (pp. 1-39). Springer Berlin Heidelberg.

Yang, F.-C., \& Kao, S.-L. (2009). An Agent Gaming and Genetic Algorithm Hybrid Method for Factory Location Setting and Factory/Supplier Selection Problems. Industrial Engineering \& Management Systems, 8(4), 228-238.

Yao, J. M. (2017). Supply chain resources integration optimisation in B2C online shopping. International Journal of Production Research, 55(17), 5079-5094.

Yu, C., Wong, T. N., \& Li, Z. (2017). A hybrid multi-agent negotiation protocol supporting supplier selection for multiple products with synergy effect. International Journal of Production Research, 55(1), 18-37.

Zair, F., Sefiani, N., \& Fourka, M. (2018). Advanced optimization model of resource allocation in B2C supply chain. Engineering Review: Međunarodni Časopis Namijenjen Publiciranju Originalnih Istraživanja s Aspekta Analize Konstrukcija, Materijala i Novih Tehnologija u Području Strojarstva, Brodogradnje, Temeljnih Tehničkih Znanosti, Elektrotehnike, Računarstva i Građevinarstva, 38(3), 328-337.

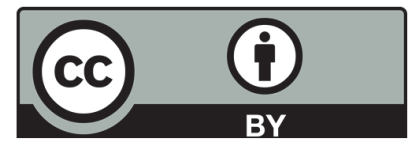

(C) 2019 by the authors; licensee Growing Science, Canada. This is an open access article distributed under the terms and conditions of the Creative Commons Attribution (CC-BY) license (http://creativecommons.org/licenses/by/4.0/). 